\title{
Design and Fabrication of Foot Operated Plate Making Machine Using Bio-Waste
}

\author{
Uday Dudhe' $^{1}$, Siddhesh Thakare ${ }^{2}$, Krunal Deotale $^{3}$, Saurabh Seware $^{4}$, Vishal Bhakare ${ }^{5}$ \\ Prof. S.G. Sonwane ${ }^{6}$ \\ ${ }^{1,2,3,4,5,6}$ Department of Mechanical Engineering,DBACER, Wanadongri, Hingna Road-441110, Nagpur
}

DOI: 10.46335/IJIES.2020.5.9.3

\begin{abstract}
In our daily life, we may find a lot of problems related to pollution, especially the earth, the ocean. The main causes of this pollution are disposable plates which are made of thermocol, plastics, ceramics and pollutant materials, they will not decompose into the earth. Bio-waste plates describe the design and fabrication of plate making machine. After a short description of the basics of the machine, this paper presents the analysis of the structure. The purpose of the foot-operated plate making machine is to make the plates from bio-waste to prevent the use of plastics. The pedal-operated plate making machine aims to make the plate and fabricate the machine within minimum cost.
\end{abstract}

\section{INTRODUCTION}

I n the world of automation, everyone needs less work but it is required high initial investment, which is not possible to the common person. Therefore, it has been trying to make something affordable to the common man and they can start their own business in their home with minimum investment. This proposal evaluates the technical feasibility and financial viability in setting up a small-scale enterprise to do the activity on manufacturing and sale plate in the small districts and all-over rural areas. In using this plate making machine, the demand for plates is increasing continuously. To satisfy demand, current productivity also should be increased. The plate making machine is used to different shapes of die \& punch in a faster production rate. This is a simple pedal-operated machine, which is manually operated with minimum power consumption. Pedal power is the transfer of energy from a human source through the use of a foot pedal and crank system. To maintain simplicity and economy in the design the locally fabricated unit has been used. Our project achieves higher safety, increases efficiency, reduces the workload and reduces maintenance costs. The objective of our project is to achieve mass production, to increase production rate, to provide an alternative for industries aiming toward reducing human effort.

\section{II- LITERATURE REVIEW}

1) In our daily life, we may find a lot of problems related to pollution, especially earth pollution. We are encouraging a lot of instant products which are made of plastics because of lower costs and requirements. The disposable plates which are made of thermocol and materials such as plastics, ceramics are land pollutant materials, they will not decompose into the earth. To avoid the above-said problem need to use natural type raw materials that easily decompose. Areca nut tree, which has leaves of big size and confines that leaf into the desired shape by using the die equipment. The design of the machine was done in CATIA software and fabrication was done by using different joining methods like welding and bolt and nuts. Real-time testing was carried out at different temperatures [6]. 
2)Paper describes the development and design and fabrication of bowl making machine. The principle of operation of the machine is based on the movement of the slider-crank mechanism. After a short description of the basics of the machine, this paper presents the analysis of the structure. The aim of the foot-operated bowl making machine is to make the bowl and fabricate the machine within minimum cost [7].

3) This paper is on the design for manufacture and assembly of a paper cup making machine for a developing economy that can be locally manufactured within an income and expenditure that suits most small to medium businesses (SMEs). The current problem is that current computer-controlled paper cup making machines on the market are expensive and therefore not affordable for a developing economy. Through wide research of how current paper cup making machines work, it was possible to come up with a low-cost effective solution. A deeper understanding of the paper cup making machine was conducted with the aid of the internet, scholarly journals and industrial visits to local companies. The manufacture of this paper cup making machine is advantageous to a developing nation by creating jobs and thus eliminating poverty [8].

4) Sheet metal punching is an important industrial process for forming mechanical parts. Aimed at generating holes on thick sheets, the punching process has been considered as a promising solution for the heavy industrial sector. The correct punching parameter choice has a direct influence on the hole quality. Since there exists rarely an analytical expression describing the relationships between these process parameters, the forming variable choice follows a series of costly tryand-error procedures on the workshop floor. A numerical simulation is a powerful tool that helps to form engineers at the try-and-error procedures. This work shows the possibility of using FE-simulations to reduce the number of experiments that has to be conducted propitiating an increased understanding concerning some punching process parameters influence. The aim is the study of the clearance influence on the punched holes quality, $8 \mathrm{~mm}$ LNE38 sheet metal. Clearances of $0.2 \%$ up to $15 \%$ between the punch and die were analyzed. The influence of the punch-die clearance on the crack propagation was also analyzed, and the results were in agreement with the literature, i.e., good results for gaps within the traditional ideal range and occurrence of burr for clearance of $15 \%$ [15].
5) This paper is mainly focusing on the cutting operation and punching operation is done independently in the current self-loader areca nut plate making machine. To conquer this, the self-loader areca nut plate making machine joins both activities, which will expand the creation rate. The fundamental concentration of the venture 'Plan and examination of semi-computerized areca nut plate making machine'2 is to outline the machine for assembling of 12-inch areca plate. The primary parts of the machine are upper bite the dust and lower kick the bucket, engine, and warming curl. The working rule of the machine follows up on water-driven constrain. The upper and lower pass on is warmed by warming curl which is controlled by power. The waterdriven constrain is instigated in the machine to move the kick the bucket in a vertical movement. As an areca nut leaf sheath is set between the passes on, the development of the bite the dust causes punching and cutting procedure in the sheath. Areca nut plates are accessible in different sizes as per pass on sizes. These plates are helpful, airtight, light in weight, solid, biodegradable. The venture plan and examination of areca nut plate making machine lessens the assembling time and expands the creation requiring little to no effort [3].

\section{III- DESIGN \& DATA COLLECTION}

\section{1) Design Sketch \\ 1) 3D Setup-}

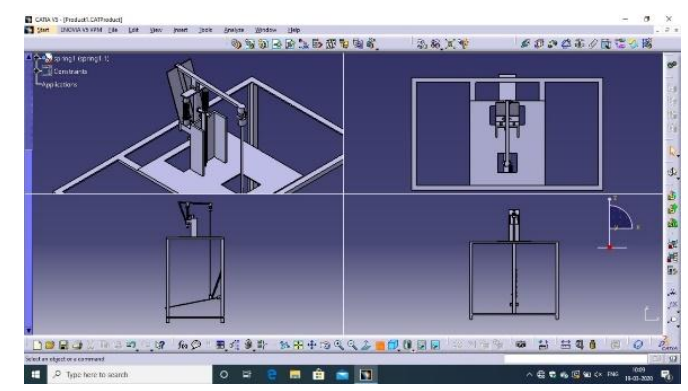

Figure 3.1.1 - 3D Sketch of Top view, Side view, Back view of Plate Making Machine

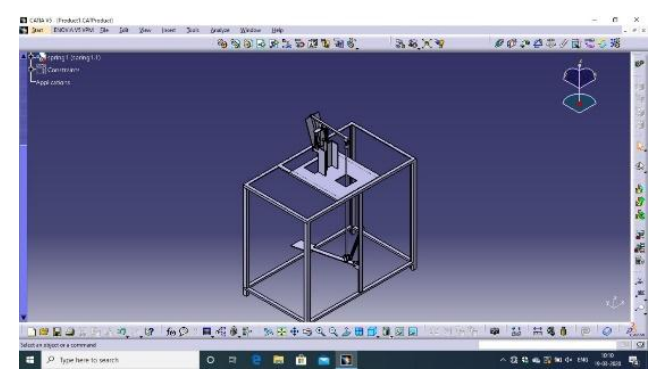

Figure 3.1.2 - 3D Sketch (Isometric View) of Plate Making Machine 
2) Mechanism use in Plate Making Machine-

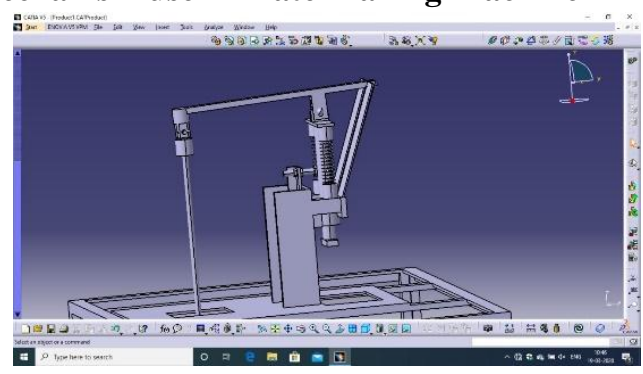

Figure 3.1.3- Mechanism use in Plate Making Machine

\section{3) 2D Setup-}

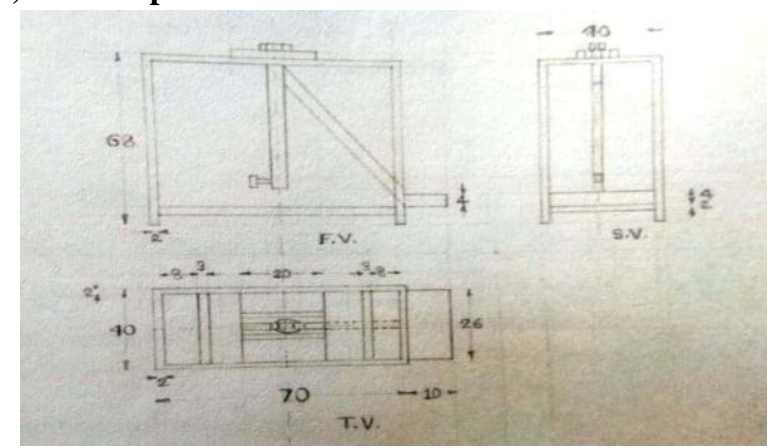

Figure 3.1.1 - 2D Sketch of Top view, Side view, Back view of Plate Making Machine

\section{4) Final Setup-}

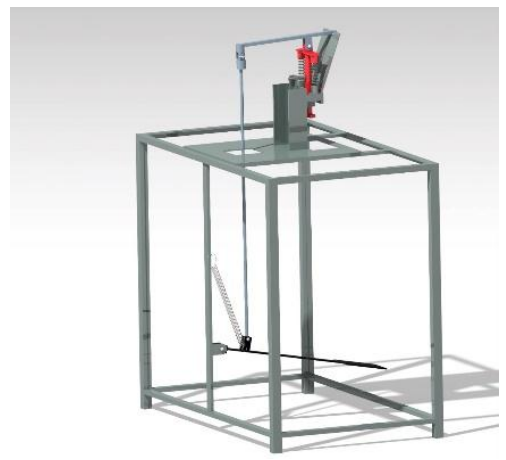

Figure 3.1.4- Final Setup of Plate Making Machine

\section{2) Data Collection-}

1) Die - Die is a specialized tool used to cut or shape material mostly using a press dies are generally customized to the item they are used to create a product made with dies range from simple paper plate to complex piece. Die may be defined as the female part of the complete tool for producing work in the press. The die of the foot-operated machine including two mating parts one of the females die and another is male die. The male die is stationary and female die moves up and down with the help of a slider-crank mechanism. The die is made up of harden steel material. The punching operation will take place as the material on lower die touches upper die, the material will be subjected to compressive stress.

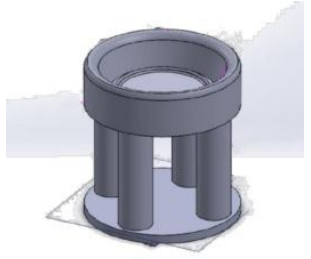

Fig.3.2.1-Circular Die

2) Punch- Punch is the male component of the die. It is the male part of die assembly and also that fastened to ram press through punching plate. Which punch matches with die shape. This punches the metal strip again the die and necessary operation. Small clearance kept between die and punch.

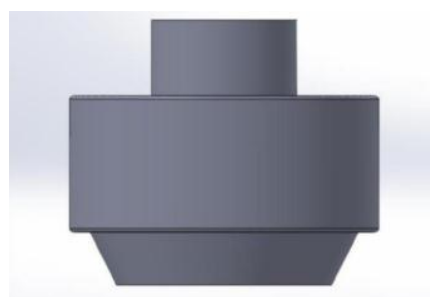

Fig.3.2.2- Circular Punch

3) Guide Block- It guides the toggle plate to move in only one direction. It provides up and down motion of the toggle plate.

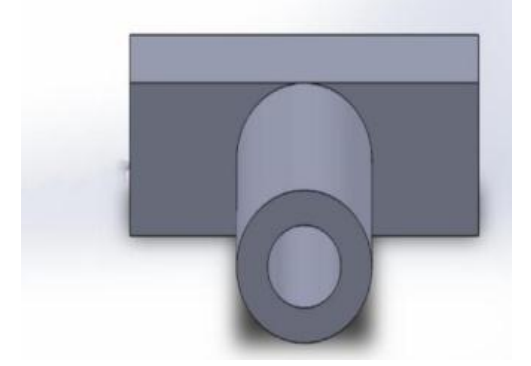

Fig 3.2.3- Guide Block

4) Plate linkage- It is connected to a pedal-operated lever and toggle plate. If we press the pedal-operated lever in a downward direction through this linkage the toggle plate moves in upward direction and punching operation is done. 


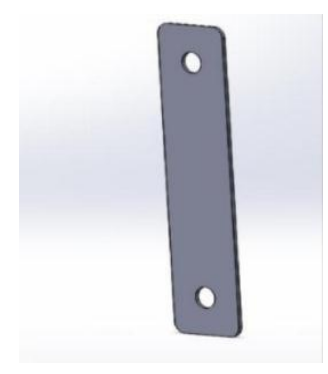

Fig.3.2.4- Plate Linkage

5) Pedal-operated lever- It is connected to plate linkage.

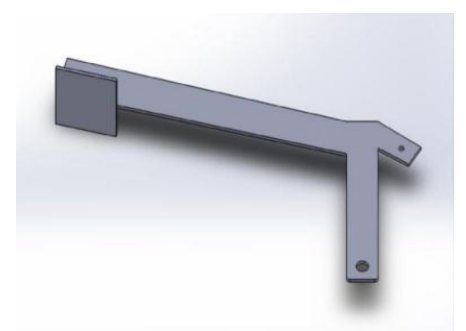

Fig3.2.5-Pedal-operated lever

6) Toggle plate- Guide block provides the movement of the toggle plate. At the upper end, the die is attached and at the lower end, it is attached to the plate linkage.

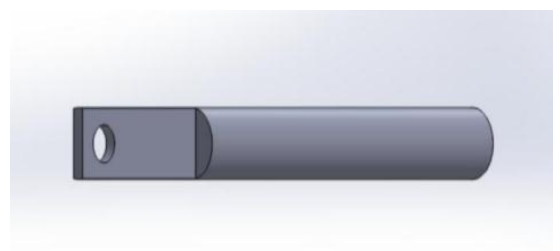

Fig.3.2.6- Toggle Plate

\section{IV- METHODOLOGY}

\section{Construction and Working Principle-}

1) Construction- The machine consists of the following components High tension spring, Die, punch, Closed and ground spring, Nut and bolt, Guide block, Plate linkage, Pedal Operated Lever, Toggle Plate, etc. The tool is mounted on a c-channel bar which gives the base for the mechanism. The die and punch mounted are made up of stainless steel which has one move up and down and another one is on lower side in axis with punch axis. Die and punch used in the machine are easily removable and can adjust as per the size required because of that die punch can give any sizes of plates. The upper mechanism consists of a flat bar and a solid rod, which is joint by weld as well as nut and bolt arrangement. The body is made by the joining L- type flat bar which is a framed which forms the base of the machine. Two springs are mounted on the upper side of the die and punch which aids in bringing the punch back to its original position after punching operation the raw material. The pedal is mounted on the lower side of the machine the whole operation can be controlled by this pedal. High tension spring is attached to the pedal rod to regain its original position.

2) Working- Very first, the force is applied to the pedal using the foot. As the force exerted on the pedal, the relative linkages also get downward attached to it. Two spring is mounted on the upper side of the tool, which aids in bringing the punch back to its original position after punching operation. Punch movement is up and down to easily doing the operation of punching to form the plate. After the punching operation, the high-tension spring plays a vital role to get the pedal back to its original position. This process simultaneously goes on the raw material of the plate for the formation of the plate.

\section{V-FUTURE SCOPE}

In our machine, most of the parts are detachable hence the replacement of the parts can be done easily. Also, the die and punch of the plate can be replaced by another type of die and punch. The manual system can be replaced by a hydraulic or pneumatic system. The purposed machine use for punching operation has a limit and can be used for small purposes and small-scale industries in rural areas. To increase volume and capacity for large scale industrial application the machine needs to be automated. This automation can be done by installing motor sensors and can be used for the required application.

\section{VI- CONCLUSION}

Plate making machine has been designed, fabricated and tested. This machine is user-friendly, low cost, maintenance cost is negligible, it can be used as a startup business and also for the village industry. There are various problems related to punching operations such as wastage of raw material, the effort required is the more, time consumed is more and the production rate is less. All these problems are being eliminated and this machine will help to increase the production rate of plates. 


\section{ACKNOWLEDGEMENT}

It is difficult to overstate gratitude to our Project Guide S.G. Sonwane. With his enthusiasm, his inspiration, and his great efforts to explain things clearly and simply, he helped to make the project fun for us. Throughout our project period, he provided encouragement, sound advice, good teaching, good company, and lots of good ideas. We would have been lost without him.

We are indebted to our HOD, Pro. G. M. Dhote and Hon. Principal Dr. V. H. Tatwawadi for all the support that they extended in helping us throughout the project period.

We want to appreciate the assistance of all members of our department for their suggestions and enthusiasm that they shared in the project.

We cannot end without thanking the Library staff, who provided us with all reference material for which we constantly bothered them all.

\section{REFERENCES}

[1] Sanchit Gaikwad, Amol Kalokhe, International Journal for Research in Engineering Application and Management, ISSN: 2494-9150, Volume-02, Issue 01, (APR 2016).

[2] Tejas Patel, Vikas Panchal, Saurin Sheth, Purvi Chauhan, 5th National Conference on Recent Advances in Manufacturing, (2015)

[3] Mohanraj KS, Vijayakumar P, Senthilkumar $R$, Gokul Karthik, International Research Journal of Engineering and Technology, e-ISSN: 2395 -0056, pISSN: 2395-0072, Volume: 04 Issue: 05, (May 2017)

[4] Viraj N. Suryawanshi, Nilesh V. Wakade, Prof. Prashant A. Narwade, International Research Journal of Engineering and Technology, e-ISSN: 2395-0056, P-ISSN: 2395-0072, Volume: 06 Issue: 05, (May 2019)

[5] Kumbhar Rohit Bhimrao, Lugade Ajinakaya Rajaram, Mullani Kamal Dilwar, Patil Appaji Pundalik, Patil Tushar Ballu, Mahadev G. Reddy, Duradundi Sawant Badkar, Trends in Machine Design, ISSN: 2455-3352, Volume 4, Issue 3, (2017)

[6] Ch. Mani Kumar, P. Rajendra Babu, International journal on Recent Researches in Science, Engineering and Technology, ISSN: 2347-6729, ISSN: 2348-3105, Volume 5, Issue 10, (Oct 2017)
[7] Dr.A.K. Bhat, Sayali Ghogale, Sushma Kadam, Pratiksha Sawant, International Research Journal of Engineering and Technology, ISSN: 2277-9655, (April 2017)

[8] Kudakwashe N. Masengere, Tawanda Mushiri, Proceedings of the International Conference on Industrial Engineering and Operations Management Bandung, Indonesia, (March 2018)

[9] Suyash B. Kamble, I.D. Burase, Avinash R. Kharat, Amol A. Nannikar, International Journal of Mechanical Engineering and Technology, Volume 7, Issue 4, (July-Aug 2016)

[10] Ankit Pawar, Arjun Pawar, Lalit Sillak, Pritish Sonawane, Amay Tipayle, International Research Journal of Engineering and Technology, p-ISSN: 2395-0072, e-ISSN: 2395 -0056, Volume-4 Issue-5, (May 2017)

[11] T.R. Gholve, Y.M. Thorat, A.R. Kashid, A.A. Mane, Prof. S.G. Koligiri, International Journal of Research Publications in Engineering and Technology, ISSN: 2454-7875, Volume-3, Issue-5, (May 2017)

[12] Ayneendra B, Sachin Hulageri, International Journal of Latest Engineering Research and Applications, ISSN: 2455-7137, Volume- 3, Issue- 5, (May 2018).

[13] Sanjay N. Havaldar, Altaf Somani, Anusha Pikle, Yash Siriah and Samiksha Patil, International Journal of Current Engineering and Technology, eISSN: 2277-4106, p-ISSN 2347-5161, (2016).

[14] Mr. Chetan P. Sable, Prof. P.D. Kamble, Mr. Dhiraj D. Dube, International Journal of Research in Aeronautical \& Mechanical Engineering, Volume-1 Issue.8, ISSN: 2321-3051, (December 2013).

[15] J. A. Soares, M. L. Gipiela, S. F. Lajarin \& P. V. P. Marcondes, The International Journal of Advanced Manufacturing Technology, ISSN 0268-3768, Volume-65, (2013). 